\title{
Supportive Care Needs and Medical Care Requests of Male Patients during Infertility Treatment
}

\author{
Kyoko Asazawa1 ${ }^{*}$, Mina Jitsuzaki², Akiko Mori' ${ }^{3}$, Tomohiko Ichikawa ${ }^{4}$, Katsuko Shinozaki ${ }^{5}$ \\ ${ }^{1}$ Department of Nursing, Tokyo Healthcare University, Tokyo, Japan \\ ${ }^{2}$ Department of Nursing, University of Occupational and Environmental Health, Fukuoka, Japan \\ ${ }^{3}$ Women's Health and Midwifery, Graduate School, St. Luke's International University, Tokyo, Japan \\ ${ }^{4}$ Graduate School of Medicine, Chiba University, Chiba, Japan \\ ${ }^{5}$ Graduate School of Health and Welfare Science, International University of Health and Welfare, Fukuoka, Japan \\ Email: *11DN001x2U-ts@slcn.ac.jp
}

How to cite this paper: Asazawa, K., Jitsuzaki, M., Mori, A., Ichikawa, T. and Shinozaki, K. (2018) Supportive Care Needs and Medical Care Requests of Male Patients during Infertility Treatment. Open Journal of Nursing, 8, 235-247.

https://doi.org/10.4236/ojn.2018.84020

Received: March 10, 2018

Accepted: April 15, 2018

Published: April 18, 2018

Copyright (C) 2018 by authors and Scientific Research Publishing Inc. This work is licensed under the Creative Commons Attribution International License (CC BY 4.0).

http://creativecommons.org/licenses/by/4.0/

\begin{abstract}
Background: This study aimed to clarify the supportive care needs and medical care requests of male patients during their infertility treatment to be able to provide them with optimal nursing care. Methods: A self-filled questionnaire survey was conducted in 411 male patients who were undergoing infertility treatment at 4 human reproductive clinics. The investigation period was from April to August 2016. This research used across-sectional study design. The submission of the filled questionnaire was taken as an indication of agreement and consent to the research. The main contents of the questionnaire were attributions, care needs, and medical care requests of male patients. The care needs were evaluated by descriptive statistics, and the free descriptions of the medical care requests were analyzed for their contents qualitatively and recursively. The study was performed after the approval of the Research Ethics Review Committee. Results: The number of valid responses was $331(80.5 \%)$. The care needs of the male patients were warm care for their wives, provision of information on their treatment, daily life information for conceiving, and evaluation data. The 6 categories of the open-ended responses were as follows: warm support, improvement of examination environment, adjustment of medical examination schedule, information provision, support from wife, and subsidy for treatment costs. These were extracted from the medical care requests by qualitative inductive analysis. Conclusions: The care needs and medical care requests of male patients undergoing infertility treatment were mainly on being provided information and supporting their wives. As supporting nursing care for these male patients, provision of sufficient in-
\end{abstract}


formation regarding the examination results and infertility treatment is recommended, and environmental considerations peculiar to male patients are necessary. Consideration for female patients is also an indispensable factor similarly to the provision of care for male patients.

\section{Keywords}

Infertility, Male, Needs Assessment

\section{Introduction}

Infertility is a worldwide problem and it affects $15 \%$ of couples who have unprotected sex [1]. Male infertility has been reported to account for $20 \%-30 \%$ [2] or $40 \%-50 \%$ of infertility in couples [3]. Moreover, the proportion of male factors as reasons for infertility has been reported to reach $55.7 \%$ [4]. Therefore, medical staff involved in infertility treatment must be aware that male factors account for about $50 \%$ of infertility causes in all couples.

Women and men who have experienced infertility were found to have dysthymia, anxiety disorders, and panic disorder from their infertility treatment, as well as a concomitant decline in their quality of life (QOL) [5]. Similarly to women, men suffer from undergoing fertility treatments both physically and psychologically. On the other hand, men undergoing infertility treatment make fewer visits than women. Even if men have identified the causes, they have less physical burden in terms of medication or treatment. However, men undergoing infertility treatment usually develop depression and anxiety [6].

The psychological symptoms of men undergoing infertility treatment include anxiety, depression, active-avoidance coping, catastrophizing, and difficulties in communicating with his partner [7]. Thus, a specific psychosocial support program and follow-up for infertile men are warranted. For most infertile women, they were found to seek more medical information as well as emotional support from the hospital staff [8]. Although there is substantial evidence on the need of infertile women for emotional support [9] [10], there is apparently no evidence on the need of men for emotional support and care for their psychological adaptation to infertility and related treatments. In treating infertility in couples, it is equally meaningful to focus on the male patients who are undergoing infertility treatment and provide them with support according to their care needs. However, reports on the nursing care needs and medical care requests of male patients remain scarce. Japan is one of the world's major infertility treatment countries. Even if the cause of infertility is considered to be equal both from the male and female partners, there is a gender culture that women should receive the fertility treatment. Although the care needs of Japanese women during infertility treatment have been clarified, those of Japanese men have not yet been clearly identified. This study aimed to clarify the nursing care needs and medical care requests of male patients undergoing infertility treatment to be able to provide 
them with optimal treatment and adequate support.

\section{Methods}

\subsection{Design}

This study was a descriptive quantitative cross-sectional questionnaire survey.

\subsection{Participants and Setting}

Data were collected by purposive sampling of participants from a convenience sample of 4 infertility clinics in the Kanto district of Japan in which the primary physicians and nursing directors have agreed to cooperate with this study. The inclusion criteria were as follows: 1) adult men undergoing infertility treatment, 2) adult men communicating in Japanese, and 3) adult men having no serious physical or physiological medical histories. The exclusion criteria were as follows: 1) patients with sexual dysfunction or severe psychiatric disorders, and 2) patients who received positive results in their pregnancy test. The sample size required for the survey was calculated using the response rate of 0.5 , the standard error of $5 \%$, and the confidence level of $95 \%(\lambda=1.96)$. Therefore, the target sample size was set at 426 participants (384/0.9).

$$
n=1.96^{2} \times \frac{0.5(1-0.5)}{0.05^{2}}=384
$$

\subsection{Procedures}

After obtaining permission from the health facilities, verbal and written information regarding the research project was provided to the participants. Submission of the completed questionnaire was considered as indicating consent from the participant. Each participant was asked to return the completed questionnaire in a sealed envelope either by post or by placing it in a collection envelope at the waiting lounge of the clinic. During the study period from April to August 2016, 411 questionnaires were distributed to eligible patients. A total of 332 (80.8\%) completed questionnaires were returned, of which 321 were suitable for analyses.

\subsection{Ethical Considerations}

The study was conducted after obtaining approval from the Ethics Committee for Epidemiological Studies at Tokyo Healthcare University (approval no. 27-33) dated January 20, 2016. Following the Declaration of Helsinki, a written explanation regarding the study objectives, methods, protection of anonymity, and voluntary basis of participation was provided to each participant. It was also explained that the collected data would only be used for this study.

\subsection{Survey Contents}

\subsubsection{Participants' Attributes}

The participants' attributes included age, length of marriage, duration of infertil- 
ity, infertility treatment period, with or without of children, cause of infertility, nature of the current treatment, frequency of changing hospitals/clinics, significant medical history, and marital status including remarriage.

\subsubsection{Care Needs of Male Patients}

The care needs of male patients consisted of 15 items with 2 response categories, namely, "Yes" or "No". These included the following items: provision of various kinds of information such as examination data, treatments, and daily life information for conceiving; different types of emotional care such as providing mental consultation, attentive hearing, and gentle polite correspondence; provisions for environment adjustments such as the waiting room and semen submission facility; various forms of support for their wives such as providing information to alleviate their burden and giving them warm care. The survey items were created by the researchers in reference to reports in the literature supporting the needs of infertile patients [11].

\subsubsection{Medical Care Requests}

The participants were asked to respond to open-ended questions to know their medical care requests for infertility treatment.

\subsection{Statistical Analysis}

Descriptive statistics of quantitative data were calculated. The presence and absence of care needs of male patients were examined between 2 groups according to their attributes using the chi-squared test. SPSS version 23.0 (SPSS, Chicago, IL, USA) was used for data analyses at a significance level of 5\%. The qualitative data from the open-ended remarks regarding the medical care requests were analyzed in terms of the description of the contents qualitatively and recursively. By noting the context described, this was coded during the comparison while considering the similarities and differences. When the level of coding abstraction was raised, this generated categories that represent the proper meaning, which facilitated the consideration of the appropriateness of category naming.

\section{Results}

During the study period, 411 questionnaires were distributed to eligible patients. A total of 332 completed questionnaires (80.8\%) were returned, of which 321 were suitable for analyses. Therefore, the response rate was $96.7 \%$.

\subsection{Patients' Attributes}

The patients' attributes are summarized in Table 1 . Their mean age \pm standard deviation was $37.9 \pm 5.2$ years (range $25-56$ ). The length of fertility treatment was 1 year and 4 months. The patients noted that the primary cause of their infertility (43.3\%) was unclear, and the secondary cause $(10.3 \%)$ was male factors. The treatment for $20.9 \%$ of the patients was assisted reproductive technology. Of these patients, $7.8 \%$ had a significant medical history and $29.9 \%$ had experienced changing hospitals. 
Table 1. Demographic data of the participants $(\mathrm{N}=321)$.

\begin{tabular}{|c|c|c|}
\hline Patient's Attributes & Mean & SD \\
\hline Age(years) & 37.9 & 5.2 \\
\hline range & \multicolumn{2}{|c|}{$(25-56)$} \\
\hline \multirow[t]{2}{*}{ Duration of infertility treatment } & \multicolumn{2}{|c|}{1 year and 4 months } \\
\hline & $\mathrm{n}$ & $\%$ \\
\hline \multicolumn{3}{|l|}{ Infertility period } \\
\hline$<2$ years & 134 & 41.7 \\
\hline$>2$ years & 187 & 58.3 \\
\hline \multicolumn{3}{|l|}{ Having a child } \\
\hline yes & 54 & 16.8 \\
\hline no & 267 & 83.2 \\
\hline \multicolumn{3}{|l|}{ Significant medical history } \\
\hline yes & 25 & 7.8 \\
\hline no & 296 & 92.2 \\
\hline \multicolumn{3}{|l|}{ Causes of infertility } \\
\hline unexplained & 139 & 43.3 \\
\hline male factor & 33 & 10.3 \\
\hline female factor & 51 & 15.9 \\
\hline male and female factors & 39 & 12.1 \\
\hline unknown & 59 & 18.4 \\
\hline \multicolumn{3}{|l|}{ Type of treatment } \\
\hline non-ART & 240 & 74.8 \\
\hline ART & 67 & 20.9 \\
\hline unknown & 14 & 4.4 \\
\hline \multicolumn{3}{|l|}{ Changed hospitals/clinics } \\
\hline yes & 96 & 29.9 \\
\hline no & 225 & 70.1 \\
\hline
\end{tabular}

${ }^{*} \mathrm{ART}=$ assisted reproductive technology.

\subsection{Care Needs of Male Patients (Figures 1-6)}

The factor structure was confirmed for each variable in the care needs measurement. Factor analysis was performed using the alpha factor for the factor extraction method and the Varimax rotation methods. The 4 subscales were extracted using 15 items. The results of the factor analysis yielded factor loadings of 0.30 or more for all items, and the cumulative contribution rate was $40.3 \%$. The reliability of the questionnaires was established using the total (0.80) and individual Cronbach's alpha coefficient of $0.66-0.71$. 
The most common answers regarding the care needs of male patients were warm support for their wives (69.2\%). Specifically, the care needs of male patients included provisions of various kinds of information such as treatment approaches $(63.2 \%)$, daily life information for conceiving $(61.7 \%)$, support for their wives $(60.1 \%)$, information on examination data $(56.1 \%)$, and support for their wives to alleviate their burden (50.5\%). The results are shown in Figure 1.

Next, the presence or absence of care needs of male patients were examined between 2 groups according to their attributes using the chi-squared test. The "changing hospital experience group" significantly needed more information on the wife's burden than the "without changing hospital experience group" $\left(X^{2}=\right.$ $4.3, p<0.05$ ) (Figure 2). The "significant medical history group" needed a counselor introduction more than the "nonsignificant medical history group" $\left(X^{2}=\right.$ 5.6, $p<0.05$ ) (Figure 3). The "significant medical history group" needed a self-help group introduction more than the "nonsignificant medical history group" $\left(X^{2}=7.3, p<0.01\right)$.The "with male factors group" significantly needed a gentle polite correspondence more than the "without male factors group" $\left(X^{2}=\right.$ 5.2, $p<0.05$ ) (Figure 4). In addition, the "male factors group" significantly needed a warm support for their wives more than the "without male factors group" ( $\left.X^{2}=4.2, p<0.05\right)$ (Figure 5). The "male and female factors group" significantly needed daily life information for conceiving more than the "without male and female factors group" was $\left(X^{2}=6.0, p<0.05\right)$ (Figure 6).

\subsection{Medical Care Requests (Table 2)}

The results of the content analysis of the open-ended responses revealed 6 categories as follows: 1) warm care, 2) improvement of examination environment, 3) adjustment of medical examination schedule, 4) information provision 5) support for wife, and 6) subsidy for treatment costs. Comments included requests

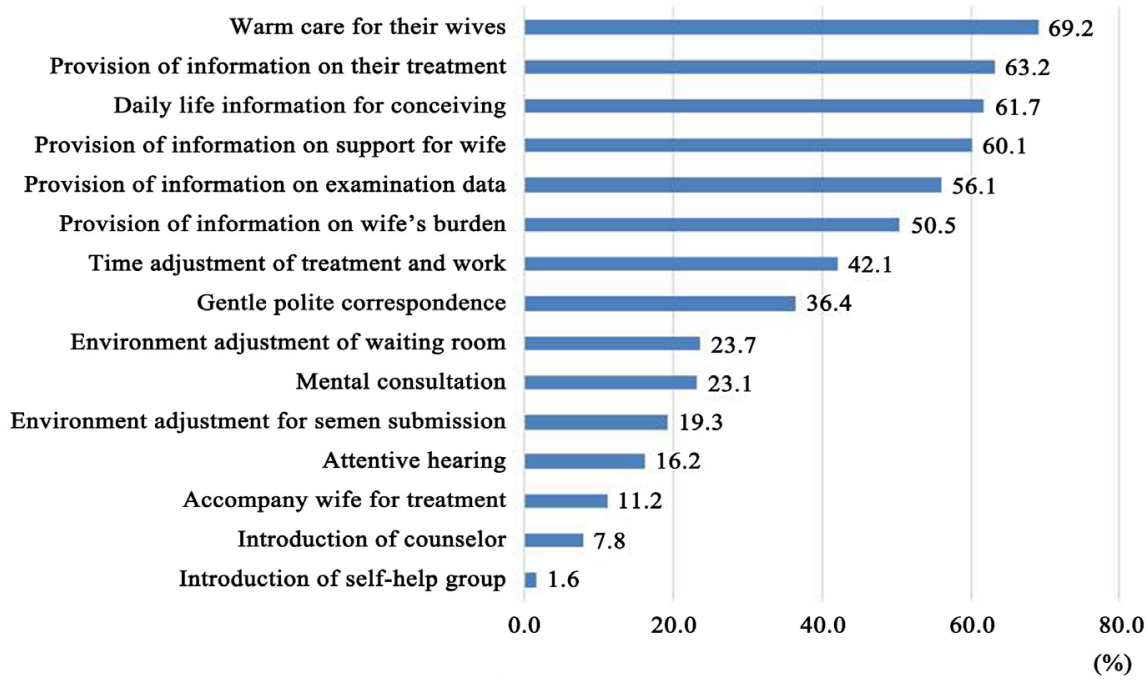

Figure 1. Care needs of infertility male patients $(\mathrm{N}=321)$. 


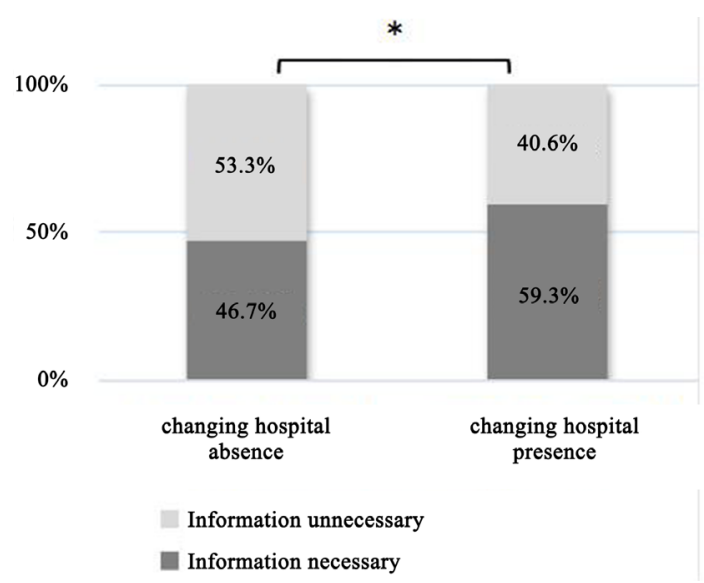

Figure 2. Provision of information on wife's burden when changing hospitals $(\mathrm{N}=321)$.

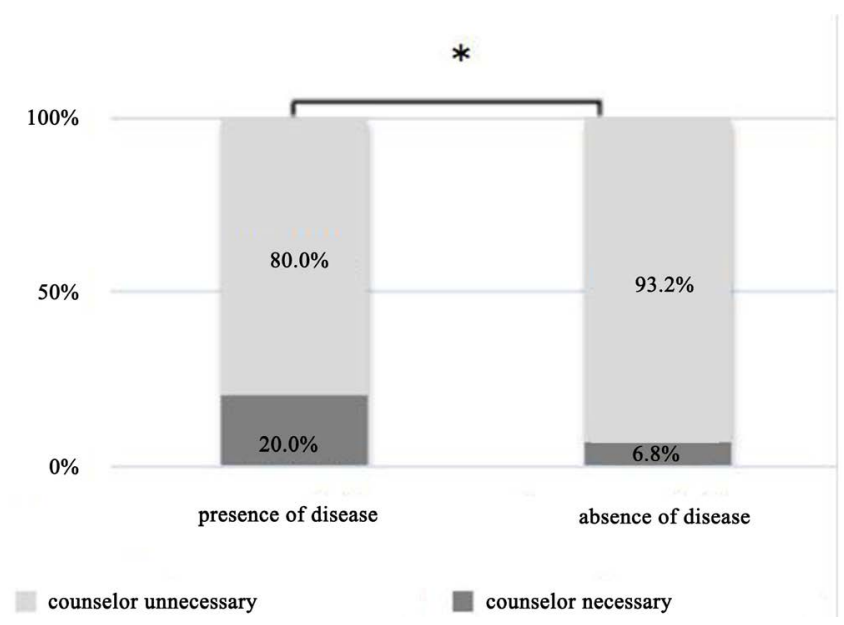

Figure 3. Request for counselor introduction request according to significant medical history $(\mathrm{N}=321)$.

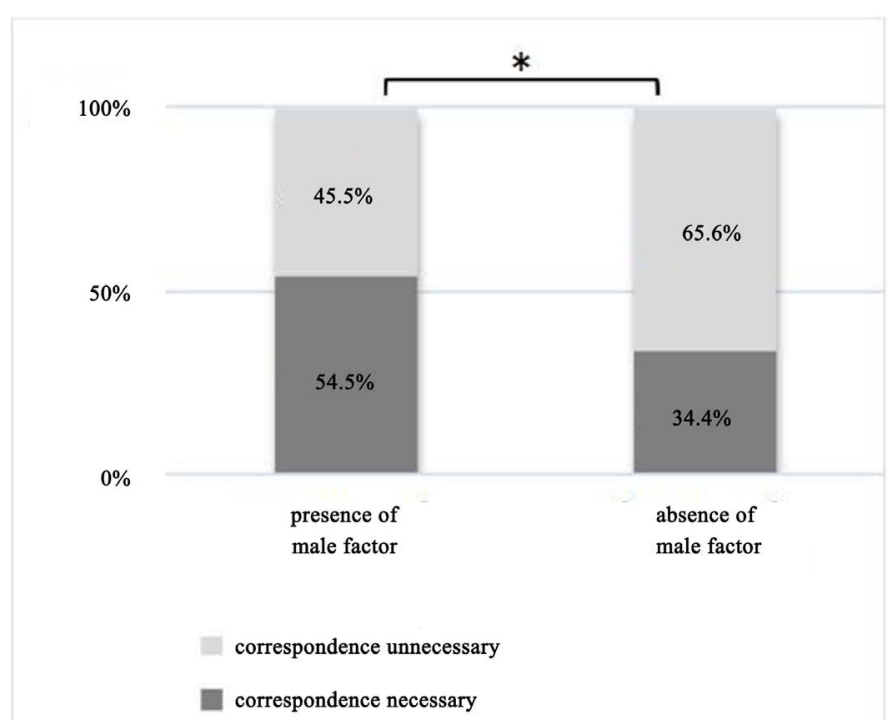

Figure 4. Request for gentle polite correspondence according to male factors $(\mathrm{N}=321)$. 


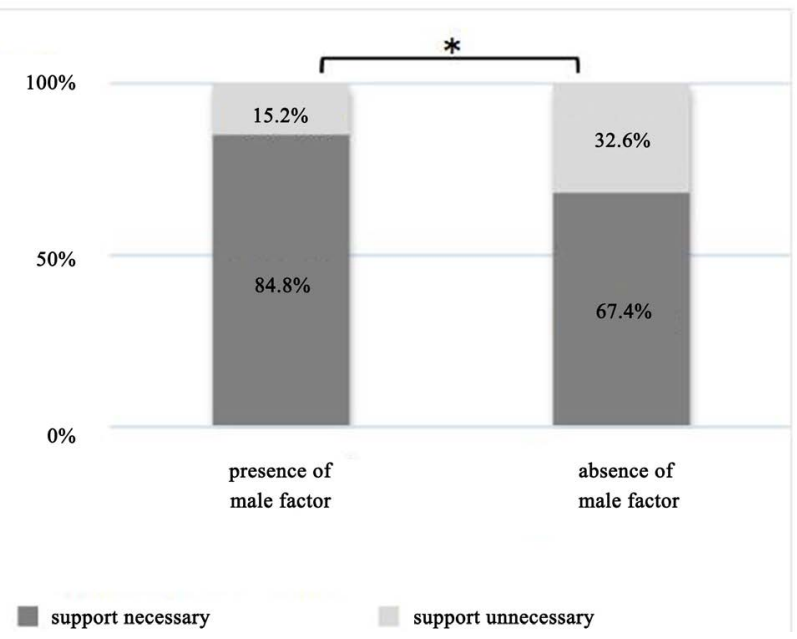

Figure 5. Request for warm support for wife according to male factors $(\mathrm{N}=321)$.

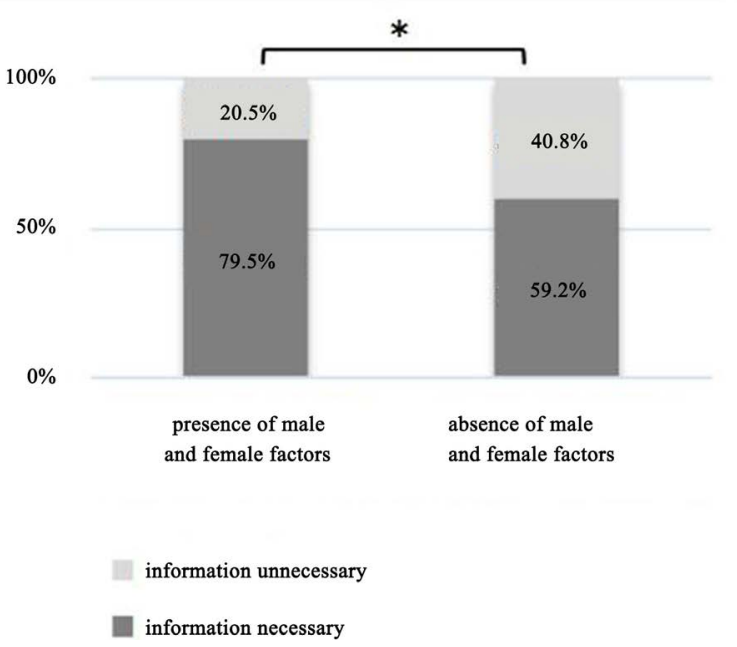

Figure 6. Request for daily life information according to male and female factors $(\mathrm{N}=321)$.

and suggestions for future improvements (Table 2). Because the questions were open-ended, not all of the respondents answered the questions and only 44 respondents were obtained.

\section{Discussion}

This study revealed the care needs and medical care requests of male patients during infertility treatment. The greatest care need of the male patients was their strong desire to have support for their wives more than a personal support. This was followed by the need for provisions of various kinds of information such as treatment, examination data, and daily life information for conceiving. Differences in the care needs were also found to be due to variations in the patients' attributes such as experiences of changing hospitals, underlying diseases, and male factors. Medical care requests were identified as warm care from 
Table 2. Medical care requests during infertility treatment $(n=44)$.

\begin{tabular}{cl}
\hline \multicolumn{1}{c}{ Category } & \multicolumn{1}{c}{ Code } \\
\hline Warm care & An atmosphere wherein questions can be easily asked \\
& Strict but very polite consultation \\
& Empathetic listening \\
& Information sharing among medical staff \\
Improvement of examination environment & Environment maintenance of the waiting room \\
& Cooperation with local governments \\
Adjustment of medical care schedule & Prolonged medical service hours \\
& Shortening the waiting time \\
& Easy-to-understand explanation of the treatment \\
policy & Information provision of daily life for conceiving \\
Information provision & Provide information on semen improvement \\
Subsidy for treatment costs & Provide information on treatment costs \\
Provide information on infertility cause & Provide information on male infertility treatment \\
& Hope for consideration for wife \\
& Improve wife's medical schedule \\
&
\end{tabular}

themselves and their wives, provisions of various kinds of information, and adjustments of the treatment environment. To relieve the psychosocial burden of infertile men and for them to be able to continue with their treatment, it is important for nurses to exert all efforts to help meet these care needs and medical care requests.

\subsection{Warm Care for Couples}

Male patients undergoing infertility treatment have significantly lower incidence of severe depressive symptoms, personal distress, and social distress [12] as well as depression than female patients [13]. In the present study, the male patients had different care needs depending on the male factors and significant medical history. Therefore, it is equally necessary to exert effort in providing warm care to male patients after their background assessment. The specific contents of warm care identified in the present study were as follows: 1) an atmosphere wherein questions can be easily asked; 2) strict but very polite consultations; 3) empathetic listening; 4) information sharing among medical staff; and 5) sympathetic support.

The necessity of information provision and the importance of patient-centered involvement were previously recognized. In particular, information provision, respect for a patient's values, continuity of care, and team com- 
petence were found to be directly associated with higher intentions of patients to comply with treatment [14]. Information provision and continuity of care were also shown to be indirectly associated with better individual well-being [15]. As the therapy content has become more specific, infertility treatment methods have also continually evolved. Thus, providing information to patients is absolutely essential. Most female infertility patients requested additional information related to infertility [16]. These included the following items: causes of infertility, how to conceive, and how to improve fertility. On the other hand, the care needs of male infertility patients were provisions of information. These included the following items: treatment approaches, daily life information for conceiving, support for their wives, information on examination data, and support for their wives to alleviate their burden (Figure 1). The difference between the male and female infertility patients was that the female infertility patients were mainly concerned with their own care and information collection. The male infertility patients needed information not only for themselves but also for their female partners. It was suggested that infertile men treated their female partners with respect.

It is important for medical professionals involved in infertility treatment to provide support not for a single patient alone but for the couple. Nonetheless, it is evident from this study that men needed more supportive care than their wives. This is because infertile men have less opportunity to visit the clinic and less chance of nursing staff involvement. Thus, identification of the specific care needs of male patients in this research may provide more information on how to provide them with optimal treatment and follow-up support.

\subsection{Limitations and Future Challenges}

There were some limitations in this study. First, since the survey was conducted at 4 fertility specialized facilities in the metropolitan area, there may be differences in the care needs of patients based on their local cities. Second, convenience sampling was used with the responses of a small number of participants ( $\mathrm{n}$ = 321) analyzed; thus, this study was not a large-scale investigation. The opinions of only 44 respondents to the open-ended questions were analyzed, which may not completely reflect the opinions of all the participants. Third, the cross-sectional design of the study does not allow for cause and effect analysis between the study variables. Because of this study design, the findings only showed an association between the attitude of an individual and the care needs at a single point in time. In the future, it will be necessary to intervene to meet these care needs, as well as to consider how the high degree of satisfaction affects the psychological state of a patient under treatment and the treatment outcome.

\section{Conclusion}

This study identified the care needs and medical care requests of male patients during their infertility treatment. The most common care need of men under- 
going infertility treatment was warm support for their wives. The care needs of male patients were provision of various kinds of information such as treatments, daily life information for conceiving, various forms of support for wife, and examination data, and various forms of support for their wives such as providing information to alleviate their burden. Differences in the care needs were likely due to differences in patient attributes such as experiences of changing hospitals, underlying diseases, and male factors. The "changing hospital experience group" needed information on the wife's burden. The "significant medical history group" significantly needed a counselor introduction and a self-help group introduction. The "with male factors group" significantly needed a gentle polite correspondence and a warm support for their wives. The "male and female factors group" significantly needed daily life information for conceiving. Medical care requests were identified as warm care for themselves and their wives, provision of various kinds of information, and adjustments of the treatment environment. To effectively relieve the psychosocial burden of infertile men and for them to be able to continue with their treatment, it is important for nurses to exert all efforts to help meet these care needs and medical care requests.

\section{Acknowledgements}

The authors thank the patients who participated in this research, as well as the facility staff and research assistants.

The authors also thank Dr. Edward Barroga (http://orcid.org/0000-0002-8920-2607), Advisor of the Academic Writing Desk of St. Luke's International University, Japan, and Associate Professor and Senior Medical Editor of Tokyo Medical University, Japan, for reviewing and editing the manuscript.

The results were presented at The 62th Annual Meeting of the Japan Society for Reproductive Medicine in 2017.

\section{Conflicts of Interest}

The authors declare that there they have no conflicts of interest associated with this study.

\section{Disclosures}

\section{Human rights statements and informed consent}

All procedures were performed in accordance with the ethical standards of the responsible committees for human experimentation (institutional and national) and the 1964 Helsinki Declaration and later amendments. Informed consent was obtained from all patients.

\section{Animal studies}

Animal studies were not performed in this study.

Approval by ethics committee

The protocol of this research project was approved by the Ethics Committee 
of Tokyo Healthcare University.

\section{References}

[1] Sharlip, I.D., Jarow, J.P., Belker, A.M., Lipshultz, L.I., Sigman, M., Thomas, A.J., Schlegel, P.N., Howards, S.S., Nehra, A., Damewood, M.D., Overstreet, J.W. and Sadovsky, R. (2002) Best Practice Policies for Male Infertility. Fertility and Sterility, 77, 873-882. https://doi.org/10.1016/S0015-0282(02)03105-9

[2] Agarwal, A., Mulgund, A., Hamada, A. and Chyatte, M.R. (2015) A Unique View on Male Infertility around the Globe. Reproductive Biology and Endocrinology, 13, 37. https://doi.org/10.1186/s12958-015-0032-1

[3] Brugh III, V.M. and Lipshultz, L.I. (2004) Male Factor Infertility: Evaluation and Management. Medical Clinics of North America, 88, 367-385.

https://doi.org/10.1016/S0025-7125(03)00150-0

[4] Bablok, L., Dziadecki, W., Szymusik, I., Wolczynski, S., Kurzawa, R., Pawelczyk, L., Jedrzejczak, P., Hanke, W., Kaminski, P. and Wielgos, M. (2011) Patterns of Infertility in Poland-Multicenter Study. Neuro Endocrinology Letters, 32, 799-804.

[5] Klemetti, R., Raitanen, J., Sihvo, S., Saarni, S. and Koponen, P. (2010) Infertility, Mental Disorders and Well-Being-A Nationwide Survey. Acta Obstetricia et Gynecologica Scandinavica, 89, 677-682. https://doi.org/10.3109/00016341003623746

[6] Fassino, S., Pierò, A., Boggio, S., Piccioni, V. and Garzaro, L. (2002) Anxiety, Depression and Anger Suppression in Infertile Couples: A Controlled Study. Human Reproduction, 17, 2986-2994.

[7] Martins, M.V., Basto-Pereira, M., Pedro, J., Peterson, B., Almeida, V., Schmidt, L. and Costa, M.E. (2016) Male Psychological Adaptation to Unsuccessful Medically Assisted Reproduction Treatments: A Systematic Review. Human Reproduction Update, 22, 466-478. https://doi.org/10.1093/humupd/dmw009

[8] Lykeridou, K., Gourounti, K., Sarantaki, A., Roupa, Z., Iatrakis, G., Zervoudis, S. and Vaslamatzis, G. (2010) What Kind of Care and Support Do Infertile Women Undergoing Fertility Treatment in Greece Expect? A Questionnaire Survey. Clinical and Experimental Obstetrics \& Gynecology, 37, 201-208.

[9] Schmidt, L., Tjørnhøj-Thomsen, T., Boivin, J. and Nyboe Andersen, A. (2005) Evaluation of a Communication and Stress Management Training Programme for Infertile Couples. Patient Education and Counseling, 59, 252-262.

https://doi.org/10.1016/j.pec.2005.05.013

[10] Domar, A.D., Clapp, D., Slawsby, E., Kessel, B., Orav, J. and Freizinger, M. (2000) The Impact of Group Psychological Interventions on Distress in Infertile Women. Health Psychology, 19, 568-575. https://doi.org/10.1037/0278-6133.19.6.568

[11] Read, S.C., Carrier, M.E., Boucher, M.E., Whitley, R., Bond, S. and Zelkowitz, P. (2014) Psychosocial Services for Couples in Infertility Treatment: What Do Couples Really Want? Patient Education and Counseling, 94, 390-395.

https://doi.org/10.1016/j.pec.2013.10.025

[12] Peterson, B.D., Sejbaek, C.S., Pirritano, M. and Schmidt, L. (2014) Are Severe Depressive Symptoms Associated with Infertility-Related Distress in Individuals and Their Partners? Human Reproduction, 29, 76-82.

https://doi.org/10.1093/humrep/det412

[13] Volgsten, A., Svanberg, S., Ekselius, L., Lundkvist, O. and Sundström Poromaa, I. (2008) Prevalence of Psychiatric Disorders in Infertile Women and Men Undergoing in Vitro Fertilization Treatment. Human Reproduction, 23, 2056-2063. 
https://doi.org/10.1093/humrep/den154

[14] Pedro, J., Canavarro, M.C., Boivin, J. and Gameiro, S. (2013) Positive Experiences of Patient-Centred Care Are Associated with Intentions to Comply with Fertility Treatment: Findings from the Validation of the Portuguese Version of the PCQ-Infertility Tool. Human Reproduction, 28, 2462-2472.

https://doi.org/10.1093/humrep/det259

[15] Gameiro, S., Canavarro, M.C. and Boivin, J. (2013) Patient Centred Care in Infertility Health Care: Direct and Indirect Associations with Wellbeing during Treatment. Patient Education and Counseling, 93, 646-654.

https://doi.org/10.1016/j.pec.2013.08.015

[16] Bennett, L.R., Wiweko, B., Bell, L., Shafira, N., Pangestu, M., Adayana, I.B., Hinting, A. and Armstrong, G. (2015) Reproductive Knowledge and Patient Education Needs among Indonesian Women Infertility Patients Attending Three Fertility Clinics. $\mathrm{Pa}$ tient Education and Counseling, 98, 364-369.

https://doi.org/10.1016/j.pec.2014.11.016 